\title{
Conhecimento social: o caso do pagamento mínimo da fatura do cartão de crédito
}

\author{
Iarê Sandra Cooper ${ }^{1}$ \\ Tania Stoltz ${ }^{2}$
}

\section{RESUMO}

Trata-se de extrato de pesquisa de mestrado relacionada à construção do conhecimento social. Objetiva-se analisar as representações de adultos jovens, usuários de cartão de crédito, quanto à forma de pagamento das faturas, mais precisamente, em relação à possibilidade de pagamento mínimo do valor da fatura. Participaram do estudo vinte adultos jovens usuários de cartão de crédito. Os dados foram coletados por meio de entrevistas individuais cujo roteiro foi elaborado a partir do método clínico de Piaget. A análise dos dados originou dez categorias descritivas do pensamento dos participantes. Neste, enfatiza-se as representações dos participantes sobre as formas de pagamento das faturas. A análise dos dados demonstra que os participantes apresentam conhecimento elementar em relação a esses aspectos e aos demais relacionados ao uso do cartão de crédito. Ressalta-se a importância da compreensão dos processos envolvidos na utilização de cartão crédito, uma vez que o seu mau uso pode resultar em sobre-endividamento, comprometendo a qualidade de vida dos sujeitos.

PALAVRAS-CHAVE: Piaget. Adultos jovens. Cartão de crédito.

Social Knowledge: the case of the Minimum Credit Card Bill Payment

\section{ABSTRACT}

It is a next ract from master's degree research that a imed to identify there

\footnotetext{
${ }^{1}$ Doutora em Educação. Universidade Federal do Paraná. Curitiba, Paraná, Brasil.E-mail:iarecooper@yahoo.com.br

${ }^{2}$ Doutora em Educação. Universidade Federal do Paraná. Curitiba, Paraná, Brasil. E-mail:tania.stoltz795@gmail.
} 
presentations of young adults, credit card users, regarding the payment of method the invoices, more precisely, in relation to the possibility of minium payment of the in voice value. Twenty young adult credit card users participated in the study. The data were collected through individual interviews whose script was drawn from the clinical method of Piaget. Analysis of the data originated tende scriptive categories of participants' thinking. In this, the participants' representation so the pay ment methods of in voices are emphasized. The analysis of the data shows that the participants present elementary know led gere garding these aspect sand the others related to the use of the credit card. It is important to understand the processes involved in the use of credit cards, since their misuse can lead to over-indebtedness, compromising the subjects' quality of life.

KEYWORDS: Piaget. Young adults. Credit card.

\section{Introdução}

Este artigo visa a analisar as representações de adultos jovens, usuários de cartão de crédito, quanto à forma de pagamento das faturas, mais precisamente, em relação à possibilidade de pagamento mínimo ou parcial do valor da fatura. Para tanto, a análise se deu a partir dos dados obtidos em estudo de mestrado ${ }^{3}$ de perspectiva construtivista de base piagetiana, inserido no campo dos estudos sobre o conhecimento social e que buscou identificar as representações de adultos jovens de Curitiba referentes aos processos de obtenção de lucro das instituições financeiras a partir da utilização do cartão de crédito.

\footnotetext{
${ }^{3}$ Trata-se de extrato de pesquisa de mestrado intitulada "Cartão de crédito: salvação ou perdição. As representações de adultos jovens sobre a obtenção de lucro das instituições financeiras” (COOPER, 2012), realizada junto ao Programa de Pós-Graduação em Educação da Universidade Federal do Paraná, sob a orientação da Profa. Dra. Tania Stoltz.
} 
Quando se fala em desenvolvimento cognitivo pode-se afirmar que, atualmente, estamos relativamente bem informados sobre os processos de desenvolvimento funcional e estrutural desde o bebê até a adolescência. Entretanto, ainda é pouco o que se sabe sobre o período que separa a adolescência da fase adulta (DANIS; SOLAR, 2001). Se por um lado, os estudos com crianças e adolescentes contribuem para a compreensão do desenvolvimento dos adultos, por outro lado, as pesquisas com jovens adultos 4 podem contribuir para avaliar o que já se sabe sobre os estádios anteriores de desenvolvimento.

Apesar de não ter tido como foco o estudo do desenvolvimento cognitivo de sujeitos adultos, os estudos de Piaget contribuem para a compreensão do desenvolvimento cognitivo destes, uma vez que descrevem o processo de desenvolvimento das estruturas do conhecimento, principalmente no que se refere às estruturas formais do pensamento.

De acordo com a teoria piagetiana (PIAGET, 1978/1924; 1979/1926; 1977/1932; 1987/1936; 1975/1946; 1958/1947; 1964), o início do desenvolvimento do pensamento formal começa por volta dos 12 anos e recebe essa designação porque, nesse estádio, os pensamentos do sujeito desprendemse do concreto e "avançam mais e mais em direção a raciocínios formais e abstratos" (KESSELRING, 2008, p. 140). A principal característica desse estádio de desenvolvimento é a inversão de sentido entre o real e o possível. O pensamento formal é essencialmente hipotético-dedutivo, sendo que,

a dedução não mais se refere diretamente a realidades concebidas, mas a enunciados hipotéticos, isto é, a proposições que se referem a hipóteses ou apresentam dados apenas como simples dados,

\footnotetext{
${ }^{4}$ Adulto jovem: fase do desenvolvimento humano que corresponde ao período entre 20 e 40 anos de segundo Papalia, Olds e Feldman, 2006.
} 
independentemente de seu caráter real: a dedução consiste então, em ligar essas suposições, e delas deduzir suas consequências necessárias, mesmo quando sua verdade experimental não ultrapassa o possível. (INHELDER, PIAGET, 1976/1955, p. 198).

Operar formalmente requer a descentração do pensamento. Liberto do concreto, agora o sujeito é capaz de fazer inferências a respeito de fatos e objetos ausentes e em relação ao futuro. É o momento da elaboração de teorias e das grandes ideias, da cientificidade do pensamento. Segundo Piaget e Inhelder (2009/1968), o pensamento formal amplia os aspectos da realidade, antes limitados e concretos, em função da possibilidade ilimitada de combinações possíveis, reforçando os poderes da inteligência dedutiva. Sendo que,

as operações formais representam, exclusivamente, a estrutura do equilíbrio final, para o qual tendem as operações concretas, ao se refletirem em sistemas mais gerais combinando entre si proposições que as exprimem. (PIAGET, 1958/1947, p. 193).

Em Piaget (1964), o pensamento formal é tido como a conclusão do desenvolvimento cognitivo em nível estrutural e a abertura ilimitada em termos de possibilidades, sem limites para o aprimoramento e a construção de novos conhecimentos. Segundo Kesselring (2008), Piaget reconhece, mais tarde, a possibilidade de desenvolvimento de outras estruturas, para além das operatório-formais. Contudo, os sujeitos alcançam o nível de pensamento operatório formal em diferentes áreas do conhecimento, de acordo com suas atitudes e especializações profissionais. A maneira como essas estruturas serão usadas não será necessariamente a mesma em todos os casos (Piaget, 1972). 
Um sujeito poderá apresentar um pensamento mais elaborado em áreas específicas do conhecimento e um pensamento elementar em outras.

Compreender as questões que envolvem o crédito e o lucro requer grande potencial de abstração, não sendo possível sem a generalização, característica do pensamento formal. A ampliação desse potencial de generalização resulta da qualidade de interação entre o sujeito e o objeto de conhecimento.

A maneira como se entende a realidade econômica e os conceitos referentes ao uso do dinheiro e do crédito é de grande interesse para os estudos envolvendo noções sociais, pois servem de modelo para a compreensão de toda a realidade social (DELVAL; PADILLA, 1999b). Dentre os campos do conhecimento social, são ao menos duas as razões para que o conhecimento econômico seja o de maior destaque dentre os estudos do desenvolvimento psicológico. Primeiro, por constituir-se um dos principais eixos da organização social, sendo o campo com o qual todos entram em contato desde muito cedo e, segundo, pelas possibilidades de estudos, principalmente experimentais que esse campo viabiliza. Apesar da dificuldade em abordar todas as noções econômicas, há elementos objetiváveis, de fácil comprovação empírica, como as questões de compra e venda e a noção de lucro, que podem ser estudados de maneira bem direta (DELVAL, 2007; DELVAL; PADILLA, 1999b).

Os estudos sobre a noção de lucro podem ser organizados a partir de três grandes enfoques. O primeiro e mais antigo enfoque, baseado em estudos evolutivos, observa a construção de estruturas cada vez mais complexas, que vão do desenvolvimento da criança ao adolescente, e que seriam determinantes para a compreensão do lucro. O enfoque adotado na maioria dos estudos é de fundamentação piagetiana e discute a existência ou não de um desenvolvimento estrutural que abrangeria tanto o conhecimento social como o conhecimento físico (STRAUSS; SCHUESSLER, 1951; STRAUSS, 1952, 1954; 
FURTH, 1980; JAHODA, 1981，1984; DELVAL，2007; DELVAL; PADILLA, 1999b). Embora sejam evocados os conceitos piagetianos de equilibração e de conflito cognitivo na construção de conceitos econômicos, os pesquisadores dividem-se entre os que relacionam a construção de conceitos econômicos ao aparecimento das operações e os que não postulam a possibilidade de analogia entre o desenvolvimento do conhecimento físico e o desenvolvimento do conhecimento social. No entanto, há concordância de que há certo atraso no desenvolvimento do conhecimento social em relação ao conhecimento físico em ambas as abordagens.

Outra abordagem concentra-se nas possibilidades da educação para a aquisição de conceitos econômicos, discutindo se o conteúdo de economia em currículos, bem como questões metodológicas relacionadas ao ensino de noções de economia, possibilitam o aprendizado de noções econômicas por meio de intervenções educativas (BERTI, 1993; BERTI; BOMBI, 1998; BERTI; BOMBI; BENI, 1986; DANIS; SOLAR, 2001). No entanto, esses estudos não explicitam claramente os processos que determinam a mudança conceitual. Esses estudos seguem basicamente as relações entre desenvolvimento e aprendizagem propostas na obra de Inhelder, Sinclair e Bovet (1975). Há ainda, estudos que enfatizam o conflito sociocognitivo no desenvolvimento de conceitos econômicos. De modo geral, esses estudos consideram que o pensamento hipotético-dedutivo é necessário para o entendimento do mundo econômico, enfatizando que os conceitos econômicos requerem mais informações do meio social e cultural que os conhecimentos físicos.

A terceira linha de estudos concentra-se na compreensão de conceitos econômicos ao término da adolescência e na idade adulta. Esses estudos justificam-se pelas mudanças conceituais no adulto a partir de sua interação com o mundo socioeconômico. Os estudos sob essa abordagem respondem à 
questão epistemológica relacionada ao conhecimento geral versus o conhecimento de domínio, investigando se o problema do conhecimento econômico é um problema de quantidade de informações trabalhadas ou de reestruturação conceitual. Esses estudos indicam mudanças significativas no pensamento econômico de estudantes universitários em relação ao nível de instrução econômica de seus cursos. Observa-se que quanto maior o nível de instrução, maior a proporção de pensamento econômico inferencial. Por essa razão e considerando o impacto do nível de instrução econômica, defendem a incorporação, no currículo universitário, da alfabetização econômica para auxiliar na transição da vida universitária para o mundo do trabalho, para o desenvolvimento de juízo crítico em torno da própria atuação no mundo de consumo e, mais do que isto, para o desenvolvimento do pensamento social, fundamental para a verdadeira cidadania (AMAR et al., 2001; AMAR et al., 2006).

Consequentemente entende-se, como um dos papéis da educação, promover o conhecimento acerca do mundo social, principalmente do mundo econômico, não apenas para que o sujeito compreenda como a sociedade se organiza, mas também de que maneira suas ações se refletem nessa sociedade, possibilitando, assim, transformações sociais.

Estando o acesso ao crédito cada vez mais amplo, é imprescindível que os sujeitos estejam aptos a usufruir criticamente destes benefícios e isso só será possível a partir da reflexão e compreensão dos fatores que influenciam esses sistemas de financiamento. Então, para que se atue de forma crítica e consciente, é preciso que se pense em uma educação para jovens e adultos que contribua para a compreensão dos processos econômicos, sobretudo em relação às questões que envolvem a compreensão dos processos de obtenção de lucro e 
aos processos envolvidos no uso de cartão de crédito ofertado, possibilitando, dentre outras coisas, a utilização adequada desse meio de crédito.

\section{Procedimentos Metodológicos}

A pesquisa foi realizada junto a adultos jovens, moradores da cidade de Curitiba, usuários de cartão de crédito provenientes de contas bancárias ou de estabelecimentos comerciais.

A idade dos participantes foi determinada a partir da definição de adulto jovem de Papalia, Olds e Feldman (2006) que corresponde ao indivíduo com idade entre vinte e quarenta anos. Neste estudo foram selecionados 10 participantes com vinte e 10 com quarenta anos de idade, caracterizando o início e o fim dessa fase do desenvolvimento, totalizando 20 participantes, sendo 5 mulheres e 5 homens com vinte anos de idade e 5 mulheres e 5 homens com quarenta anos de idade. Os participantes foram selecionados a partir dos contatos pessoais da autora e por intermédio de indicações. Estando o sujeito dentro do perfil da amostra da pesquisa e concordando em participar do estudo, a coleta de dados foi agendada e realizada em local de melhor conveniência para o participante.

Para a realização da coleta de dados deste estudo fez-se uso do método clínico de Piaget (1926) por se tratar de um método cuja "essência é a intervenção sistemática do pesquisador em função do que o sujeito vai fazendo ou dizendo. [...] O pesquisador, mediante suas ações e suas perguntas, procura compreender melhor a maneira como o sujeito representa a situação e organiza sua ação" (DELVAL, 2002, p.12). Este método foi criado por Piaget e apresentado na obra $A$ representação do mundo na criança (1926), que aborda a 
forma como o pesquisador pode desenvolver a entrevista e os variados tipos de respostas que podem ser alcançados com a utilização do método clínico.

O método clínico permite acompanhar o curso do pensamento dos sujeitos ao longo de uma dada situação, fazendo sempre novas perguntas para esclarecer respostas anteriores. A entrevista é constituída por perguntas básicas que devem ser respondidas por todos os participantes e por perguntas que são acrescentadas conforme as respostas dadas pelos sujeitos, estando sempre orientadas pelo objetivo da pesquisa que está sendo realizada (DELVAL, 2002). Por ser um método flexível, o entrevistador conduz a entrevista buscando sempre elucidar a maneira como o sujeito chega às suas concepções, visando a tornar claras e conscientes as explicações destes.

Para alcançar os objetivos desse estudo foi elaborado, como instrumento de coleta de dados, um roteiro de entrevista que, após a análise de um especialista, foi testado a partir de um estudo piloto, o que permitiu a reformulação e reconsiderações de algumas perguntas visando ao aprimoramento desse instrumento.

As entrevistas foram realizadas individualmente e gravadas, com a autorização dos participantes, para possibilitar a transcrição literal das respostas. Os protocolos com as transcrições das entrevistas foram analisados, inicialmente, de forma individual e, para a análise do conjunto de dados, as respostas dos participantes foram dispostas em planilhas descritivas, possibilitando a análise do conjunto de respostas dadas por todos os participantes da pesquisa, originado 10 categorias descritivas do pensamento dos participantes em relação aos processos de utilização de cartão de crédito. 


\section{Resultados}

A partir das planilhas descritivas e de acordo com a apresentação e regularidade nas respostas, foram instituídas dez categorias representativas do pensamento dos sujeitos em relação ao uso do cartão de crédito e em relação às suas concepções sobre as formas de obtenção de lucro das instituições financeiras, a saber:

1) Quantidade de cartões de crédito;

2) Formas de obtenção de cartão de crédito;

3) Formas de pagamento com cartão;

4) Controle de gastos com cartão;

5) Formas de pagamento das faturas;

6) Vantagens e desvantagens das financeiras conforme forma de pagamento das faturas;

7) Limite de crédito;

8) Prejuízos e benefícios na utilização de cartão de crédito;

9) Recomendações para a utilização de cartão de crédito e;

10) Representações referentes aos processos de obtenção de lucro das instituições financeiras.

Aqui será dada ênfase às categorias 5 - Formas de pagamento das faturas, e 6 - Vantagens e desvantagens das financeiras conforme forma de pagamento das faturas. Mas, antes de apresentar os resultados dessas categorias, segue breve exposição das demais.

Em relação à quantidade e forma de obtenção dos cartões de crédito, os dados demonstram que, dos 39 cartões totalizados pelos participantes da pesquisa, são os homens que detêm o maior número de cartões, somando 22 . 
Em relação à idade, os participantes com quarenta anos de idade, somando homens e mulheres, totalizam 24 cartões de crédito. Dos 39 cartões acumulados pelos 20 participantes, 27 foram obtidos a partir da oferta de bancos, na abertura de conta corrente ou em lojas, supermercados e demais estabelecimentos comerciais. Apenas 12 cartões foram solicitados pelos participantes junto às financeiras.

Quanto à forma de pagamento na aquisição de bens e serviços utilizando cartão, apenas um homem, com vinte anos de idade, afirma que utiliza apenas a função débito do cartão, visando evitar o endividamento. O pagamento de despesas utilizando as funções débito e crédito do cartão é usual para 3 homens com vinte anos de idade e 4 com quarenta anos. São as mulheres, 4 com vinte anos de idade e 4 com quarenta anos, que afirmam utilizar exclusivamente a função crédito do cartão.

A categoria forma de pagamento com cartão originou uma subcategoria que analisa a relação forma de pagamento e preço a ser faturado. As respostas dos participantes da pesquisa demonstram que a maioria não relaciona a forma de pagamento ao valor final dos produtos ou serviços que estejam adquirindo, afirmando que o preço é sempre o mesmo, independentemente se pago em dinheiro, no débito, no crédito rotativo ou parcelado do cartão.

A categoria controle de gastos com o cartão de crédito permite avaliar se e como os participantes realizam o controle das despesas faturadas no cartão. Os resultados demonstram que apenas 2 homens com vinte anos e 2 homens e 1 mulher com quarenta anos de idade declaram não controlar seus gastos com cartão de crédito. No entanto, a investigação permitiu observar que, o que os participantes definem como controle, na realidade, trata-se apenas de simples conferências dos valores cobrados em fatura.

A categoria limite de crédito apresenta a forma como os participantes 
utilizam o limite e as suas concepções sobre as vantagens e desvantagens na utilização do limite. Dentre os participantes com vinte anos de idade, 3 mulheres e 3 homens afirmam que não costumam utilizar todo o limite ofertado pelas financeiras de cartão de crédito. $\mathrm{O}$ mesmo ocorre com 5 mulheres e 4 homens com quarenta anos de idade. No entanto, dos 5 homens com quarenta anos de idade, 4 afirmam que só há vantagens na utilização do limite e 1 afirma que há vantagens e desvantagens no limite de crédito. Dentre os participantes com vinte anos de idade, 4 mulheres e 3 homens afirmam que só há desvantagens na utilização do limite, 1 mulher vê apenas vantagens e 2 homens afirmam que há tanto vantagens quanto desvantagens na utilização do limite.

Quanto aos possíveis prejuízos ou benefícios para os usuários de cartão de crédito, dos participantes com vinte anos de idade, 2 mulheres e 2 homens acreditam haver apenas benefícios, 2 mulheres acreditam que há prejuízo e 1 mulher e 3 homens acreditam que fica tudo na mesma, nem prejuízos nem benefícios. Para os participantes com quarenta anos de idade, 3 mulheres e 5 homens veem apenas benefícios na utilização do cartão de crédito e 2 mulheres acreditam que fica tudo na mesma.

Em relação aos possíveis prejuízos ou benefícios para as financeiras de cartão de crédito, dos participantes com vinte anos de idade, 3 mulheres e 5 homens afirmam que as financeiras obtêm apenas benefícios e, para 2 mulheres, as financeiras não têm nem benefícios nem prejuízos quando os clientes utilizam cartão de crédito. Para os participantes com quarenta anos de idade, 4 mulheres e 5 homens afirmam que as financeiras só têm benefícios e 1 mulher acredita que fica tudo na mesma, ou seja, as financeiras não obtêm nem benefícios nem prejuízos com a utilização do cartão de crédito.

Sobre as recomendações para a utilização do cartão de crédito, 1 mulher e 
2 homens com vinte anos de idade e 2 homens e 2 mulheres com quarenta anos afirmam que indicariam a aquisição e o uso do cartão para amigos e 3 mulheres com vinte anos afirmam que não indicariam. Para 1 mulher e 3 homens com vinte anos e 3 mulheres e 3 homens com quarenta anos de idade, a indicação para aquisição e utilização do cartão de crédito dependerá do perfil do usuário. De acordo com esses participantes, o perfil ideal do usuário de cartão de crédito seria o de uma pessoa controlada, que compra apenas o que necessita e não contrai dívidas maiores que sua receita mensal.

Quanto à categoria que corresponde às representações referentes aos processos de obtenção de lucro das instituições financeiras, os dados revelam que, de modo geral, os participantes não compreendem os processos envolvidos nas transações com cartões de crédito e nem nas relações com as demais transações realizadas pelas financeiras.

Retornando o tema a ser tratado aqui - as representações dos participantes em relação ao pagamento do valor mínimo da fatura -os dados que originaram a categoria referente à forma de pagamento das faturas revelam que 5 mulheres e 4 homens com vinte anos de idade e 4 mulheres e 4 homens com quarenta anos de idade afirmam pagar as faturas em dia e no valor integral. Os demais participantes, 1 homem com vinte anos e 1 homem e 1 mulher com quarenta anos de idade, afirmam pagar apenas o valor mínimo ou parcial da fatura.

Um exemplo interessante, em relação à forma de pagamento das faturas, é o caso do participante Célio, assistente de produção que afirma possuir ao menos oito cartões de crédito provenientes de contas bancárias, dos quais utiliza dois nas compras pessoais e os outros cede para que seus parentes, que não dispõem de outro meio de crédito, possam adquirir bens e serviços. Quando questionado sob a forma como efetua o pagamento das faturas de seu cartão, 
Célio se refere aos dois que ele utiliza como seus e aos demais como "deles", dando a ideia de que os demais não estão sob sua responsabilidade, conforme extrato de entrevista que segue.

E como você efetua o pagamento da fatura na maioria das vezes? $E u$ tenho pagado, pelo menos, é... O que é meu, eu pago, o que vem ali eu pago à vista. É, com 30 dias, né? Quando é do pessoal, eu pago o mínimo deles. É, o mínimo do cartão, mas é dividido entre eles, né? Como que vocês fazem? Digamos: tem três pessoas usando o mesmo cartão, daí um paga 80, outro paga 150, outro paga 40... É assim que eu pago. Daí dá o mínimo ali. Daí cada um paga o mínimo. Daí cada um dá um pouco e paga o mínimo. E o restante da fatura? Vai ficando, né? Vai ficando. E quem paga...? Eles mesmo vão pagando. E tem alguma taxa, juro...? Não. Não. Se tiver eles me pagam. Se a empresa cobrar alguma coisa a mais eles pagam. Entendeu?

Extrato de protocolo de entrevista com participante Célio, 40 anos. (COOPER, 2012, p. 202).

Os riscos de sobre-endividamento, quando do pagamento de apenas o valor mínimo da fatura também são descritos pelos participantes. Ressalta-se que, no caso dos participantes com vinte anos de idade, os relatos, na maioria das vezes, correspondem às experiências de terceiros e não às experiências pessoais, como na afirmação da bartender Ângela: "Porque eu já ouvi falar que, se você paga só aquele mínimo, ele vem acrescentado depois" (COOPER, 2012, p. 122).

Como já expresso anteriormente, foram também investigadas as representações dos participantes sobre as vantagens e desvantagens das financeiras, conforme a forma como os usuários de cartões de crédito efetuam o 
pagamento das faturas. Segundo os dados correspondentes a esta categoria, 4 mulheres e 5 homens com vinte anos de idade e 5 mulheres e 4 homens com quarenta anos acreditam que as financeiras obtêm vantagens quando os usuários pagam parcialmente ou com atraso as suas faturas. Uma mulher com vinte anos e um homem com quarenta anos afirmam que, nesses casos, não há nem prejuízos nem benefícios para as financeiras.

Para o caso do pagamento integral e no vencimento, 3 mulheres e 1 homem com vinte anos e 2 mulheres e 4 homens com quarenta anos de idade acreditam que as financeiras obtêm vantagens. Interessante ressaltar o relato da participante Bruna, com quarenta anos de idade, que afirma que as financeiras têm prejuízo quando as faturas são pagas integralmente e na data de vencimento: "Eu acho que ela sai perdendo porque ela prefere que eu pague a taxa mínima, que eu entre no rotativo... É... Eu acho que eles preferem que eu... Que a pessoa atrase. Eu acho que eles perdem." (COOPER, 2012, p. 127). $\mathrm{E}$, para os demais participantes, as financeiras não obtém benefícios nem prejuízos quando as faturas são pagas em dia e integralmente.

\section{Discussão}

Os resultados da pesquisa, obtidos a partir de uma pequena amostra selecionada, demonstram que são os homens que tendem a possuir o maior número de cartões de crédito, o que pode ser justificado pela possível existência de um modelo patriarcal, onde o homem assume o papel de provedor do sustento da família que, em muitos casos, está limitado às despesas da casa, mas também ao sustento de sua esposa e filhos, abrangendo, em alguns casos, os irmãos, cunhados e demais parentes e agregados. Os dados demonstram ainda que a maioria dos cartões é obtida de modo quase que compulsório, uma 
vez que foram poucos os participantes que relataram ter solicitado cartão de crédito às financeiras ou aos estabelecimentos comerciais.

Dentre o grupo masculino que possui a maior quantidade de cartões, são os participantes do grupo com quarenta anos de idade os detentores da maioria dos cartões. Este fato pode resultar do aumento das responsabilidades financeiras pessoais, familiares e profissionais que, muitas vezes, implica a abertura de novas contas bancárias e a adesão a cartões de financiamento de instituições comerciais particulares (lojas de departamentos, supermercados, lojas de materiais de construção). A adesão aos cartões de lojas e demais instituições pode justificar a solicitação "espontânea" destes cartões pelo grupo participante feminino, sendo elas, na maioria dos casos, as responsáveis pelas compras domésticas.

De acordo com os resultados da pesquisa, é mais vantajoso comprar parcelado, principalmente produtos com alto valor de custo, já que os lojistas informam que o valor parcelado é o mesmo que o valor à vista, sem cobranças de juros. Assim, os clientes são induzidos ao uso do crédito rotativo ao entenderem que não há vantagens em pagar à vista. Mesmo ao reconhecerem os riscos da utilização indevida do cartão, os participantes declaram considerar apenas as vantagens em seu uso. Afirmam, por exemplo, que o limite, além de ser uma forma de controlar seus gastos, é uma excelente forma de adquirir bens ou serviços pelos quais não poderiam pagar de outra forma.

Importante ressaltar que, ainda que fazendo uso cotidianamente de cartão, alguns participantes revelam não compreender as diferenças entre as formas de pagamento com o cartão e, tampouco, utilizam-se de meios eficientes de controle dos gastos pessoais com o cartão de crédito.

Quanto à compreensão dos processos envolvidos no uso de cartão de crédito, o estudo demonstra que os participantes, adultos jovens, desconhecem 
os processos que envolvem a utilização do cartão ficando, desse modo, suscetíveis aos riscos e às armadilhas desse modelo de crédito. Dentre elas, destaque para a possibilidade de não pagar o valor total da fatura, entendida como uma possibilidade de prorrogar o vencimento de suas dívidas, não considerando que essa atitude poderá resultar em processo de sobreendividamento ${ }^{5}$, muitas vezes conhecido como "bola de neve".

Apesar de a maioria dos participantes afirmar que pagam as faturas em dia e no valor integral, suas respostas demonstram considerar o pagamento do valor mínimo ou de parte do valor total da fatura como uma alternativa viável em caso de impossibilidade de quitação. Os participantes veem o pagamento do valor mínimo como um jeito de pagar valores menores de juros na fatura subsequente. Há ainda os que afirmam não haver cobrança de juros ao se pagar o valor mínimo na data de vencimento da fatura, sendo os juros cobrados somente em caso de atraso no pagamento. Outros entendem o pagamento do valor mínimo da fatura como uma oportunidade, proporcionada pelas financeiras, para que seus clientes mantenham em dia o pagamento das faturas, oportunizando a manutenção de seus nomes "limpos", uma vez que, assim, não serão inseridos no Serviço de Proteção ao Crédito - SPC.

Ao afirmar que o pagamento do valor mínimo da fatura impede que seu nome entre nos cadastros de devedores como SERASA e SPC, os sujeitos parecem não perceber que, ao pagar apenas o valor mínimo ou parcial, além das financeiras garantirem o recebimento, adiantado, dos juros cobrados pelo

\footnotetext{
${ }^{5}$ Sobre-endividamento corresponde à situação em que o sujeito não consegue cumprir com seus compromissos financeiros, correndo o risco de comprometer a subsistência familiar. De acordo com Zarrenner (2007), o papel do sujeito no sobre-endividamento pode ser ativo ou passivo, sendo que, no primeiro caso, o sujeito contribui ativamente ao colocar-se em situação de impossibilidade de pagamento, adquirindo dívidas superiores à sua receita mensal e, no segundo caso, o sujeito encontra-se sobre-endividado por conta de circunstâncias que fogem de seu controle como desemprego, despesas extras com saúde, dentre outras.
} 
refinanciamento ${ }^{6}$, não há o bloqueio do crédito do usuário. O sujeito, mesmo não conseguindo quitar as despesas que já acumulou, continua com o crédito liberado, podendo efetuar novas aquisições, o que pode ocasionar o sobreendividamento, comprometendo o orçamento pessoal ou familiar e, consequentemente, sua qualidade de vida.

Mesmo quando verbalizam que o pagamento parcial da fatura pode resultar em processo de sobre-endividamento, ou "bola de neve", as respostas dos participantes demonstram que eles veem na possibilidade de pagar apenas uma parte do valor da fatura, uma oportunidade que as financeiras "oferecem" para que seus clientes mantenham seu crédito. Essas afirmações demonstram que o pensamento desses sujeitos apresenta características do estágio operatório concreto e até do pré-operatório (INHELDER; PIAGET, 1976/1955; PIAGET, 1978/1924, 1979/1926; 1977/1932; 1987/1936; 1975/1946; 1958/1947; 1964), uma vez que apresentam ideias quase que infantilizadas em relação às financeiras, acreditando que a possibilidade de pagamento mínimo das faturas seja apenas mais uma vantagem oferecida pelas financeiras aos seus clientes, com único intuito de ajudar.

\section{Conclusão}

A análise geral dos dados e das referidas categorias, permite concluir que os adultos jovens, participantes do estudo, apresentam uma compreensão muito elementar em relação aos processos de obtenção de lucro das instituições financeiras e sobre os processos que envolvem a utilização do cartão de crédito.

A possibilidade de pagamento de valor mínimo ou parcial da fatura,

\footnotetext{
${ }^{6}$ Ao efetuar uma compra parcelada com o cartão de crédito o indivíduo está recorrendo a um financiamento. Caso não consiga pagar alguma das faturas, pagando apenas uma parte do valor, o restante da fatura será refinanciado, cobrado posteriormente em próxima fatura, acrescido de juros, muitas vezes abusivos.
} 
evidencia que os partícipes da pesquisa não compreendem que, pagando o valor mínimo, o crédito continua disponível para compras com o cartão, o que pode resultar em sobre-endividamento, pois, com a manutenção do crédito, poderão efetivar novas compras e, uma vez que na fatura do mês subsequente serão cobrados os valores pendentes do mês anterior, além dos juros sobre o remanescente e as novas compras efetuadas.

Os participantes parecem não perceber que, mesmo parecendo ser um grande alívio não precisar pagar o valor total de uma fatura, ao estar desprovido financeiramente, o uso abusivo desta "vantagem" trata-se, na verdade, de um grande embuste, uma vez que pode resultar em descontrole de gastos, sobre-endividamento e, consequentemente, no comprometimento da receita mensal pessoal e ou familiar, prejudicando sua qualidade de vida.

A ideia que os sujeitos têm das financeiras como parceiras que provêm os recursos para a aquisição de bens e serviços é semelhante às representações dos adolescentes estudados por Jahoda $(1981,1984)$ que viam o banco como uma instituição amiga e sem fins lucrativos. Os participantes demonstram entender que o crédito ofertado pelas financeiras por meio de cartão e, principalmente, a possibilidade de não quitação do valor total da fatura, realizando apenas o pagamento de valor mínimo ou parcial, trata-se de uma fonte quase mágica de realizações de seus desejos, vendo as financeiras como provedoras de suas necessidades. Esse pensamento assemelha-se aos achados nos estudos com crianças e adolescentes que demonstram vislumbrar o mundo social isento de conflitos e em que as desigualdades sociais são entendidas e aceitas como um processo social natural (ARAÚJO, 2010; CASTORINA, 2005; CASTORINA; LENZI, 2000; DELVAL, 2007; DELVAL; PADILLA, 1999b; FURNHAM, 1990; FURNHAM; CLEARE; 1988; FURTH, 1980; GANUZA, 
1999; LAUER-LEITEet al., 2010; PARRAT-DAYAN, 2007; STOLTZ; PARRATDAYAN, 2007; STOLTZ et al., 2014).

A não compreensão desses fatores, apresentada pelos adultos jovens participantes da pesquisa que, em tese, encontram-se no estádio formal do desenvolvimento, pode ser explicada ao entender que, de acordo com a teoria piagetiana, as operações formais podem estar presentes em situações que envolvam as especialidades do sujeito, ou seja, em que ele qualitativamente interaja mais. Ressalta-se que o estádio formal implica o fechamento do desenvolvimento cognitivo em nível estrutural. No entanto, as possibilidades para o refinamento e a elaboração de novos conhecimentos a partir das operações formais são ilimitadas. Deve-se considerar que cada indivíduo poderá alcançar esse estádio de desenvolvimento em áreas distintas, conforme suas aptidões e especializações. Entendendo que a forma como essas estruturas serão empregadas pelos sujeitos não será necessariamente a mesma em todos os casos (PIAGET, 1972).

Estudar o desenvolvimento cognitivo dos adultos é de suma importância para fundamentar a elaboração de propostas pedagógicas para jovens e adultos que vislumbrem a construção das noções socioeconômicas, como a noção de lucro, por exemplo (STOLTZet al., 2014; OTHMAN; STOLTZ, 2017). Desse modo, destaca-se a importância do desenvolvimento de práticas pedagógicas voltadas à educação econômico-financeira de jovens e adultos que oportunize a compreensão dos processos envolvidos no uso de cartão de crédito, uma vez que este é tido como o meio de crédito mais relacionado às situações de sobreendividamento pessoal (VELUDO-DE-OLIVEIRA; IKEDA; SANTOS, 2004; DONADIO; CAMPANARIO; RANGEL, 2012).

Importante ressaltar que o acesso à informação não implica, necessariamente, em conhecimento ou em transformação da ação. Portanto, a 
prática pedagógica deve oportunizar que o sujeito reflita sobre as próprias ações, compreendendo, além dos fatores externos, os fatores internos envolvidos na sua relação como cartão de crédito (PIAGET, 1977, 1978), resultando na aquisição de bens e serviços, com ou sem o uso de cartão de crédito, de forma consciente.

É importante esclarecer que esse trabalho não tem a intenção de avaliar a utilização do cartão de crédito, mas sim, as representações que os sujeitos têm em relação ao uso do cartão e a obtenção de lucro por parte das financeiras. Nesse sentido, considera-se que o cartão de crédito pode ser um excelente instrumento para a aquisição de bens e serviços, desde que os usuários sejam capazes de avaliar de forma crítica e consciente suas necessidades e os riscos e benefícios que podem estar implícitos no uso do cartão.

\section{Referências}

AMAR, J.; ABELLO, R.; DENEGRI, M.; LLANOS, M. La comprensión del funcionamiento bancario en la adolescencia ¿Crónica de un sobreendeudamiento anunciado? Psicologia desde el Caribe, Universidad del Norte, Barranquilla, Colombia, n.8, Jul-Dic, p. 94-109, 2001.

AMAR, J.; ABELLO, R.; DENEGRI, M.; LLANOS, M. Análisis de las representaciones acerca de la economía en jóvenes universitarios del Caribe colombiano. Investigación y desarrollo, v. 1, n. 14, p. 152-173, 2006.

ARAÚJO, R. M. B. O pensamento econômico das crianças: para iniciar o debate. Revista Tecer, Belo Horizonte, v. 3, n. 5, nov., 2010. Disponível em: $<$ https://www.google.com.br/search?client=safari\&rls=en\&q=Revista + Tecer++Belo+Horizonte+\%E2\%80\%93+vol.+3,+no+5,+novembro+2010\&ie=UTF-8\&oe=UTF8\&gfe_rd=cr\&ei=tfQLV9mGK_Kp8we2joKYBA>. Acessoem: 28 deMarço de 2016.

BERTI, A. Fifth graders' ideas on bank functions and interest before and after a lesson on banking. European Journal of Psychology of Education, v. 8, p. 183-193, 1993.

BERTI, A.; BOMBI, A. S. The child's construction of economics. Tradução inglesa de G. Duveen. Cambridge: Cambrigde University Press, 1998. 
.; BOMBI, A. S.; DE BENI, R. Acquiring economic notions: profit. International. Journal of Behavioral Development, v. 9, p. 15-29, 1986.

CASTORINA, J. Construcción conceptual y representaciones sociales: el conocimiento de la sociedad. Buenos Aires: Editorial Miño y Dávila, 2005.

CASTORINA, J.; LENZI, A. M. (orgs.) La formación de los conocimientos sociales en los niños: Investigaciones psicológicas y perspectivas educativas. Barcelona. Editorial Gedisa, 2000.

COOPER, I. S. Cartão de crédito: salvação ou perdição? As representações de adultos jovens sobre instituições financeiras e utilização de cartão de crédito. 268f. Dissertação (Mestrado em Educação) - Universidade Federal do Paraná, UFPR, Curitiba, 2012.

DANIS, C.; SOLAR, C. Aprendizagem e desenvolvimento dos adultos. Tradução de Joana Chaves. Lisboa: Instituto Piaget. 2001.

DELVAL, J. Introdução à prática do Método clínico: descobrindo o pensamento das crianças. Tradução de Fátima Murad. Porto Alegre: Artmed, 2002.

. Aspectos de la construcción del conocimiento sobre la sociedad. Revista IIPSI, Madrid, v. 10, n. 1, p. 9-48, 2007.

DELVAL, J.; PADILLA, M. El desarrollo del conocimiento sobre la sociedad. In.: LÓPEZ, F.; ETXEBARRÍA, I.; FUENTES, M. J.; ORTIZ, M. J. (Coord.). Desarrollo afectivo y social. Madrid: Pirámide, 1999b.

DONADIO,R.; CAMPANARIO, M. A.; RANGEL, A. S. O papel da alfabetização financeira e do cartão de crédito no endividamento dos consumidores brasileiros. REMark - Revista Brasileira de Marketing, São Paulo, v. 11, n. 1, p. 75-93, jan./abril, 2012. Disponível em: <http://www.revistabrasileiramarketing.org/ojs2.2.4/index.php/remark/article/view/2281/pdf_70>. Acesso em: 29 de Março de 2016.

FURNHAM, A. Parental attitudes towards pocket money/allowances for children. Journal of Economic Psychology, v. 22,p. 397-329, 1990.

FURNHAM, A.; CLEARE, A. School children's conceptions of economics: Prices, wages, investments, and strikes. Journal of Economic Psychology, v.9, p. 467-479, 1988.

FURTH, H. G. The world of grown-ups: Children's conceptions of society. New York: Elsevier, 1980. 
GANUZA, F. B. La construcción de nociones sociales. Revista Psicodidáctica, Universidaddel País Vasco Vitoria-Gazteis, España, n. 9, 1999. Disponível em:<http://www.redalyc.org/articulo.oa?id=17500903>. Acesso em: 6 de Abril de 2016.

INHELDER, B.; PIAGET, J. Da lógica da criança à lógica do adolescente: ensaio sobre a construção das estruturas operatórias formais. Tradução de Dante Moreira Leite. São Paulo: Pioneira, 1976. (Ed. original. 1955).

INHELDER, B.; BOVET, M.; SINCLAIR, H. Aprendizagem e estruturas do conhecimento. São Paulo: Saraiva, 1974/1977.

JAHODA, G. The development of thinking about economic institutions: the bank. Cahiers de Psychologie, v. 1, p. 55-73, 1981.

The development of think ingabout socio-economic systems. In: TAJFEL, H. (ed.) The social dimension. Cambridge: Cambridge University Press, v. 1, 1984.p. 6988

KESSELRING, T. Jean Piaget. Educs: Caxias do Sul, 2008.

LAUER-LEITE, I. D.; MAGALHÃES, C. M. C.; LORDELO, E. R.;LELIS, I. L. Socialização econômica: conhecendo o mundo econômico das crianças. Estudos de Psicologia, v. 2, n. 15, Mai.-Ago., 2010. Disponível em: www.scielo.br/epsic. Acesso em: 28 de Março de 2016.

OTHMAN, Z.A.S.; STOLTZ, T. Compra uma bala aí, tio? A noção de lucro como eixo central para a compreensão do mundo econômico-social. Curitiba: Appris, 2017.

PAPALIA, D. E.; OLDS, S. W.; FELDMAN, R. D. Desenvolvimento Humano. Porto Alegre: Artmed, 2006.

PARRAT-DAYAN, S. A discussão como ferramenta para o processo de socialização e para a construção do pensamento. Educação em Revista, Belo Horizonte, v. 45. p. 1323, 2007. Disponível em: <http://www.scielo.br/pdf/edur/n45/a02n45.pdf>. Acesso em 17 de Novembro de 2015.

PIAGET, J. Psicologia da Inteligência. Rio de Janeiro: Fundo de Cultura, 1958. (Ed. orig. 1947).

. Development and learning Journal of Research in Science Teaching, New York, v. 2, n. 3, p. 176-186, 1964.

. Intellectual Evolution from Adolescence to Adul thood. Human Development, Genève, Univ. de Genève, n.15, p. 1-12, 1972. 
- A formação do símbolo na criança - Imitação, jogo e sonho, imagem e representação. 2 ed. Tradução de Álvaro Cabral e Cristiano M. Oiticica. Rio de Janeiro: Zahar Editores, 1975. (Ed. orig. 1946).

. O julgamento moral na criança. Tradução de Elzon Lenardon. São Paulo: Mestre Jou, 1977a. (Ed. orig. 1932).

- A Tomada de consciência. Tradução de Edson Braga de Souza. São Paulo: Melhoramentos, Ed. USP, 1977.

- Fazer e compreender. Tradução de Christina Larroudé de Paula Leite. São Paulo: Melhoramentos, Ed. USP, 1978.

- O raciocínio na criança. 2 ed. Tradução de Valerie Rumjanek Chaves. Rio de Janeiro: Record,1978. (Ed. orig. 1924).

A representação do mundo na criança. Tradução de Rubens Fiúza. Rio de Janeiro. Ed. Record. 1979 (Ed. orig. 1926).

. O nascimento da inteligência na criança. 4 ed. Tradução de Álvaro Cabral. Rio de Janeiro: LTC Editora, 1987. (Ed. orig. 1936).

PIAGET, J.; INHELDER, B. A psicologia da criança. Tradução de Octavio Mendes Cajado. Rio de Janeiro: DIFEL, 2009. (Ed. Orig. 1968).

STRAUSS, A. L. The development and transformation of monetary meanings in the child. American Sociological Review,v. 17, p. 275-286, 1952.

. The development of conceptions of rules in children. Child Development, v. 25, n. 3, p. 193-208, 1954.

STRAUSS, A.L.; SCHUESSLER, K. Socialization, logical reasoning, and concept development in the child. American Sociological Review, v. 16, p. 514-523, 1951.

STOLTZ, T.; COSTA, R. R. S.; PIECZARKA T.; OTHMAN, Z. A. S., COOPER, I.; D’AROZ, M. S. Revista Eletrônica Científica Inovação e Tecnologia, v. 1, n. 9, p. 01-15, 2014.

STOLTZ, T.; PARRAT-DAYAN, S. Educação e incluso social: uma leitura possível a partir de Piaget. In: GUERIOS, E; STOLTZ, S. (Org.). Educação, Inclusão e Exclusão Social: contribuições para o debate. Curitiba: Aos Quatro Ventos, v. 1, 2007.p. 95-104. 
VELUDO-DE-OLIVEIRA T. M.; IKEDA, A. A.; SANTOS, R. C. Compra compulsiva e a influência do cartão de crédito. Mercadologia. v. 44, n. 3, Jul-Set, 2004. Disponível em: <http://www.scielo.br/pdf/rae/v44n3/v44n3a07.pdf>. Acesso em: 31 de Maio de 2013.

ZERRENER, S. A. Estudo sobre as razões para o endividamento da população de baixa renda. Dissertação (Mestrado em Ciências Administrativas), Universidade Estadual de São Paulo - USP, São Paulo, 2007.

Recebido em 02 de outubro de 2017. Aprovado em 25 de novembro de 2017. 